\title{
CIVIL ENGINEERING MATERIALS
}

Nagaratnam Sivakugan | Carthigesu T. Gnanendran | Rabin Tuladhar | M. Bobby Kannan

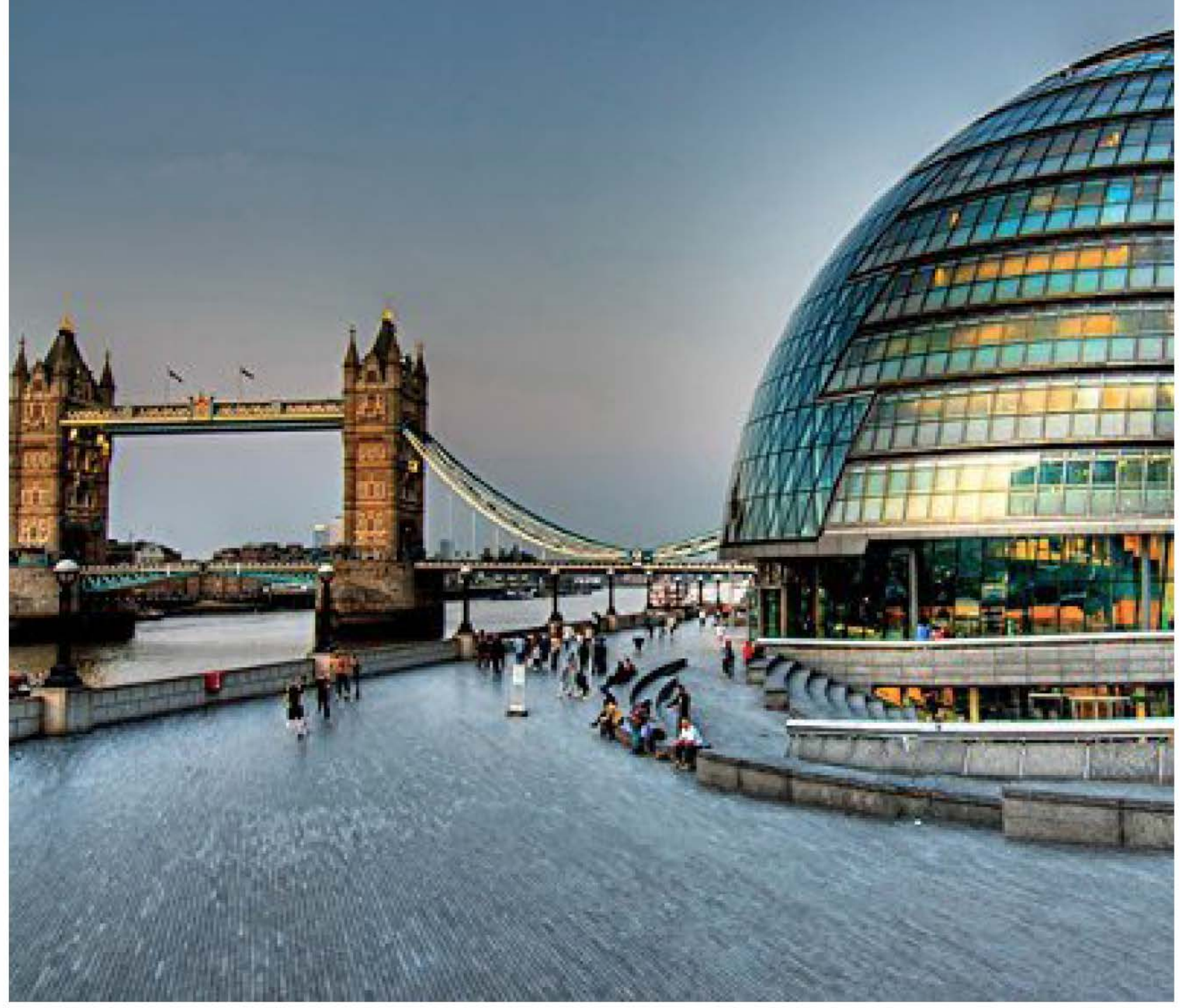




\section{Civil Engineering Materials}

Nagaratnam Sivakugan

James Cook University, Australia

Carthigesu T. Gnanendran

The University of New South Wales

at the Australian Defence Force

Academy, Australia

Rabin Tuladhar

James Cook University, Australia

M. Bobby Kannan

James Cook University, Australia

$$
\begin{aligned}
& \text { CENGAGE } \\
& \text { Learning. }
\end{aligned}
$$


$\because$ CENGAGE

$-$

\section{Civil Engineering Materials, \\ First Edition}

Authors: Nagaratnam Sivakugan,

Carthigesu T. Gnanendran,

Rabin Tuladhar, and M. Bobby Kannan

Product Director, Global Engineering: Timothy L. Anderson

Associate Media Content Developer: Ashley Kaupert

Product Assistant: Teresa Versaggi

Marketing Manager: Kristin Stine

Director, Higher Education Production: Sharon L. Smith

Content Project Manager: Megan Guiliani

Production Service: RPK Editorial Services, Inc.

Copyeditor: Lori Martinsek

Proofreader: Jason Pankoke

Indexer: Shelly Gerger-Knechtl

Compositor: SPi Global

Senior Art Director: Michelle Kunkler

Cover and Internal Designer: Stratton Design

Cover image: Photo Art by Mandy/Moment/Getty Images

Intellectual Property

Analyst: Christine Myaskovsky Project Manager: Sarah Shainwald

Text and Image Permissions Researcher: Kristiina Paul

Manufacturing Planner: Doug Wilke

\section{(C) 2018 Cengage kearning}

ALL RIGHTS RESERVED. No part of this work covered by the copyright herein may be reproduced or distributed in any form or by any means, except as permitted by U.S. copyright law, without the prior written permission of the copyright owner.

For product information and technology assistance, contact us at Cengage Learning Customer \& Sales Support, 1-800-354-9706.

For permission to use material from this text or product. submit all requests online at www.cengage.com/permissions.

Further permissions questions can be emailed to permissionrequest@cengage.com.

Library of Congress Control Number: 2016952402

ISBN: $978 \cdot 1-305-38664-8$

\section{Cengage Learning}

20 Channel Center Street

Boston, MA 02210

USA

Cengage Learning is a leading provider of customized learning solutions with employees residing in nearly 40 different countries and sales in more than 125 countries around the world. Find your local representative at www.cengage.com.

Cengage Learning products are represented in Canada by Nelson Education Ltd.

To learn more about Cengage Learning Solutions, visit www.cengage.com/engineering.

Purchase any of our products at your local college store or at our preferred online store www.cengagebrain.com.

Unless otherwise noted, all items (C) Cengage Learning.

Printed in Canada

Print Number: 01 Print Year: 2016 
1.1 Introduction

1.2 Stress-Strain Relations and Constitutive Models

1.2.1 Some Simple Material Models 4

1.2.2 Other Material Models 6

1.3 Types of Loadings

1.4 Special Loading Situations

1.4.1 Generalized Stress-Strain Relationships 12

1.4.2 Plane Strain Loading 15

1.4.3 Plane Stress Loading 17

1.4.4 Axisymmetric Loading 18

1.5 Strain-Displacement Relations

1.6 Equations of Equilibrium

1.7 Laboratory Measurements and Measuring Devices

1.8 Material Variability and Sample Statistics

1.9 Numerical Modeling

1.10 Standards, Units, and Safety

1.11 Sustainability

1.12 Summary

Exercises

\section{Chapter 2 Chemistry of Materials}

2.1 Introduction

2.2 Atomic Structure and Bonding

2.2.1 Atomic Structure 31

2.2.2 Bonding 33

2.3 Arrangement of Atoms

2.4 Classification of Materials

2.5 Imperfection in Materials

2.6 Strengthening in Materials

48

2.7 Characterization of Materials

50 
2.7.1 X-Ray Diffraction (XRD) 50

2.7. Optical Microscope 50

2.7 .3 Electron Microscopes 52

2.7.4 Atomic Force Microscope (AFM) 54

2.8 Summary

Exercises

References

3.1 Introduction 58

3.2 Civil Engineering Applications

3.2.1 Traditional Geotechnical Applications 59

3.2.2 Backfilling Underground Mines 59

3.2.3 Land Reclamation Using Dredge Spoils 60

3.3 Formation of Soils

3.3.1 Elements of Earth 61

3.3.2 Igneous, Sedimentary, and Metamorphic Rocks 63

3.3.3 Residual and Transported Soils 65

3.4 Soils versus Other Engineering Materials

3.5 Soil Classification

3.6 Compaction and Earthworks

3.6.1 Moisture-Density Relationships 69

3.6.2 Laboratory Tests 71

3.6.3 Field Compaction, Specifications, and Control 72

3.7 Permeability

3.7.1 Darcy's Law 73

3.7.2 Typical Values 74

3.7.3 Laboratory and Field Tests 74

3.8 Strength and Stiffness

3.8 .1 Failure in Soils 75

3.8.2 Deformations in Soils 76

3.8.3 Effective Stress Theory and Drained/Undrained Loading 76

3.8.4 Laboratory and Field Measurements 77

3.9 Measurements of Soil Properties

3.9.1 Laboratory Tests 79

3.9.2 In Situ Tests 79

3.9.3 Instrumentation 80

3.10 New Materials 80

3.11 Summary

Exercises

References 
$\begin{array}{llr}\text { Chapter } 4 & \text { Rocks } & 86\end{array}$

4.1 Introduction 86

4.2 Rock Engineering Applications $\quad 87$

4.2.1 Rocks as Construction Materials 87

4.2.2 Other Civil Engineering Applications, using Rocks 89

4.3 Common Rocks in Construction 90

4.4 Rock Mass and Intact Rock 91

4.5 Strength and Stiffness of Intact Rocks 92

4.5.1 Rock Cores and RQD 93

4.5.2 Strength and Stiffness Parameters 95

4.6 Laboratory Tests for Intact Rocks 101

4.7 Field Tests for Rocks 105

4.8 Rock Mass Classification 108

4.9 Rockfills 108

$\begin{array}{ll}4.10 \text { Summary } & 109\end{array}$

Exercises 110

References $\quad 112$

$\begin{array}{llr}\text { Chapter } 5 \quad \text { Aggregates } & 114\end{array}$

5.1 Introdnction 114

5.2 Origin, Geology and Classification of Parent Rocks 115

$\begin{array}{lll}5.3 & \text { Properties and Testing of Aggregates } & 117\end{array}$

5.3.1 Particle Size and Grading 118

5.3.2 Types of Grading and Relationship with Density 120

5.3.3 Shape and Surface Texture 128

5.3.4 Strength and Stiffness 132

5.3.5 Hardness, Toughness, and Abrasion Resistance 133

5.3.6 Soundness and Durability 136

5.3.7 Chemical Stability of Aggregate in PCC 137

5.3.8 Cleanness and Deleterious Substances 138

5.3.9 Affinity for Asphalt Cement 138

5.3.10 Moisture and Asphalt Binder Absorption 139

5.3.11 Relative Density (or Specific Gravity) and Bulk Density 140

5.4 Uses of Aggregates

5.5 Lightweight and Heavyweight Aggregates

5.6 Aggregates from Industrial By-Products and Waste

5.7 Handling, Transportation, and Storage of Aggregates 149

5.8 Summary 
References 153

Chapter 6 Geosynthetics 154

6.1 Introduction $\quad 154$

6.2 Types of Geosynthetics, Polymers Used, Manufacture, and Common Use

6.2.1 Types of Geosynthetics 155

6.2.2 Polymers Used in Geosynthetics 155

6.2.3 Geotextiles 157

6.2.4 Geogrids 160

6.2.5 Geonets 161

6.2.6 Geomembranes 162

6.2.7 Geocells 164

6.2.8 Geomats 164

6.2.9 Geocomposites-Geosynthetic Clay Liners

(GCLs), Prefabricated Vertical Drains (PVDs),

Geopipes, Geofoams, and Others 164

6.3 Properties and Testing of Geosynthetics

6.3.1 Tensile Properties and Testing 168

6.3.2 Fill-Soil Interface Shear Properties and Testing 171

6.3.3 Hydraulic-or Flow-Related Properties and Testing 174

6.3.4 Endurance, Integrity, Durability and Long.

Term Performance-Related Properties and Testing 179

6.4 Functions, Mechanisms

and Engineering Applications

183

6.4.1 Reinforcement 183

6.4.2 Separation 188

6.4.3 Filtration 189

6.4.4 Drainage 191

6.4.5 Containment 192

6.4.6 Erosion Control 193

6.4.7 Typical Examples of Geosythetics Use in the Field 193

6.5 Selection of Geosyrthetics

6.5.1 Available versus Required Property 197

6.5.2 Selection of a Geosynthetic 201

6.6 Summary

Exercises

References

Chapter 7 Asphalt Cement and Hot Mix Asphalt Concrete

7.1 Introduction

7.2 Types of Asphalt Cements or Bituminous Materials 
7.3 Common Asphalt Cement Products and Their Grading

7.3.] Standard Penetration Grading 211

7.3.2 Viscosity Grading 211

7.3.3 Aged Residue Grading 214

73.4 Performance Grading 215

7.3.5 OtherAsphalt Products 215

7.4 Typical Uses of Asphaltic Materials

7.5 Properties and Testing

of Asphalt Cement

7.5.1 Consistency and Rate of Curing of Asphalt Cement 220

7.5.2 Durability and Other Properties of Asphalt Materials 223

7.6 Overview of Pavements

7.7 Bituminous Surfacing Treatments and Sealing in Pavements

7.8 Asphalt Concrete

7.8.1 HMA Design 234

7.8.2 Density and Voids Analysis of HMA 235

7.8.3 Marshall Method 241

7.8.4 Superpay'e Mix Design 243

7.8.5 HMA Production 245

7.8.6 Characterization of IMAA for Pavement Design 247

7.9 Use of Additives and Recycling

7.10 Summary'

Exercises

References

\section{Chapter 8 Cement and Concrete}

8.1 Introduction

8.1.1 History of Concrete 254

8.1.2 Advantages of Concrete 255

8.1.3 Limitations of Concrete 256

8.2 Constituents of Concrete

8.2.1 Portland Cement 257

8.2.2 Supplementary Cementitious Material 263

8.2.3 Water 266

8.2.4 Aggregates 267

8.2.5 Admixture 272

8.3 Different Stages of Concrete

8.3.J Plastic State 274

8.3.2 Setting State 275

8.3.3 Hardening State 275 
8.4 Properties of Fresh Concrete

8.4.1 Workability 275

8.4.2 Consistency 276

8.4.3 Cohesiveness 278

8.4.4 Early-Age Performance of Concrete 278

8.5 Site Practice of Concrete

8.5.1 Compaction 282

8.5.2 Finishing 283

8.5.3 Curing 284

8.6 Properties of Hardened Concrete

8.6.1 Compressive Strength 285

8.6.2 Tensile Strength of Concrete 287

8.6.3 Modulus of Elasticity of Concrete 289

8.6.4 Poisson's Ratio 289

8.6.5 Creep in Concrete 289

8.6.6 Shrinkage in Concrete 290

8.6.7 Durability of Concrete 291

8.7 Concrete Mix Design

8.7.1 Mix Design Procedure 294

8.8 Snmmary

Exercises

References

\section{Chapter 9 Metals and Alloys}

9.1 Introduction

9.2 Ferrous Alloys

309

9.2.1 Iron-Carbon Diagram 310

9.2.2 Steels 311

9.2.3 Cast Irons 314

9.2.4 Stainless Steels 314

9.2.5 Heat-Treatment Techniques 315

9.3 Nonferrous Metals and Alloys

9.3.1 Copper 316

9.3.2 Aluminum 317

9.3.3 Magnesium 317

9.4 Types of Failures

9.4.1 Fracture 318

9.4.2 Fatigue 321

9.4.3 Creep 323

9.4.4 Corrosion 324

9.5 Summary

Exercises

References 
10.1 Introduction

10.2 Advantages of Steel

10.3 Limitations of Steel

10.4 Iron- and Steel-making

10.4.1 Basic Oxygen Steelmaking (BOS) 335

10.4.2 Electric Arc Furnace (EAF) 336

10.5 Wrought Iron

10.6 Cast Iron

338

10.7 Carbon Steel

338

10.8 Structural Steel

10.8.1 Hot-Rolled Steel 342

10.8.2 Cold-formed Steel 344

10.8.3 Reinforcing bars 345

10.9 Heat Treatment of Steel

10.9.1 Quenching 347

10.9.2 Tempering 347

10.9.3 Annealing 348

10.10 Mechanical Properties of Steel

10.10.1 Tension test 348

10.10.2 Poisson's Ratio (v) 351

10.10.3 Shear Modulus of Elasticity (G) 351

10.11 Summary

Exercises

References

Chapter 11 Polymers, Ceramics, and Composites

357

11.1 Introduction

11.2 Polymers

11.2.1 Chemistry 359

11.2.2 Thermosetting and Thermoplastic Polymers 361

11.2.3 Mechanical Properties 362

11.2.4 Degradation 362

11.3 Ceramics

11.3.1 Chemistry 364

11.3.2 Mechanical Properties 365

11.3.3 Glass-Ceramics 366

11.4 Composites

11.4.1 Fiber-Reinforced Plastics 367

11.4.2 Metal Matrix Composites 370 
11.4.3 Ceramic Matrix Composites 371

J].4.4 Failure 371

J1.4.5 Applications 37.1

11.5 Summary

Exercises

References

\section{Chapter 12 Wood}

12.2 Advantages of Lumber

12.3 Limitations of Wood

12.4 Structure of Wood

12.7 Anisotropic Behavior of Wood

12.8 Conversion and Processing of Wood

12.8.1 Flat or Plain Sawing 382

12.8.2 Quarter Sawing 382

12.8.3 Rift sawing 382

12.9 Seasoning of Wood

12.10 Defects in Wood

12.11 Degradation of Wood and Preservative Treatment

12.11.1 Degradation of wood 386

12.11.2 Protective Coatings and Preservative Treatments 386

12.12 Physical Properties of Wood

12.12.1 Density and Specific Gravity 387

12.11.1 Moisture Content 387

12.13 Mechanical Properties of Lumber

12.13.1 Modulus of Elasticity 389

12.13.2 Compressive Strength 389

12.13.3 Moclulus of Rupture 389

12.13.4 Tensile Strength 389

12.13.5 Creep 390

12.13.6 Determination of Mechanical Properties

12.14 Engineered Lumber Products

12.14.J Laminated Veneer Lumber (LVL) 391

12.14.2 Glued Laminated Lumber (Glulam) 392

12.14.3 Cross Laminated Timber (CLT) 392 
12.14.4 I-Beams 392

12.14.5 Plywood 392

12.15 Summary

Exercises

References

Chapter 13 Sustainability of Construction Materials 396

13.1 Introduction 396

13.2 Sustainable Development 396

13.2.1 Embodied Energy and Operational Energy 398

13.2.2 Life-CycleAssessment (LCA) 400

13.3 Sustainability of Construction Materials 402

13.3.1 Cement and Concrete 403

13.3.2 Steel 406

13.3.3 Wood 406

13.3.4 Soils, Rocks, and Aggregates 407

13.3.5 Asphalt Concrete 408

13.4 Summary

409

Exercises

410

References

411

Appendix A Unit Conversions

Index 
Materials science and engineering is a multidisciplinary area that is offered in undergraduate and graduate programs at many leading universities. It covers all engineering materials such as metals, ceramics, plastics, composites, and nanomaterials. When it comes to traditional engineering undergraduate programs such as civil, mechanical, electrical, or chemical engineering, their specific materials science educational needs are quite different. While civil engineers deal mostly with steel, concrete, timber, and soils, their mechanical engineering counterparts are interested in different alloys and composite materials. With rapid economic development and the scarcity of natural resources, the use of synthetic materials (e.g., polymers, composites), industrial byproducts (e.g., slag, fly ash), recycled materials and their combinations with traditional materials (e.g., concrete and soils) has recently become more prevalent in civil engineering projects. Hence, there is a growing need for civil engineers to learn more about these advanced materials in addition to traditional materials.

Civil engineering mainly deals with the design and construction of civil infrastructure (e.g., dams, embankments, roads, buildings and bridges) and the provision of services such as water supply and sewerage. Civil engineering projects involve the use of various materials for design and construction. It is commonly expected that civil engineers have an in-depth knowledge of these conventional and advanced materials to select the materials sensibly, determine the material properties, and effectively carry out the design and construction.

Civil Engineering Materials covers all major traditional civil engineering materials through separate chapters. Sustainability is an important consideration these days among civil and construction engineering professionals. It is and will be a critical element in the material selection process. Chapter 13 discusses the sustainability, life cycle analysis, and other important issues relevant to civil and construction materials.

The civil engineering materials course is almost always taught in a broad-brush approach rather than providing comprehensive coverage. Generally, students learn the subject in the early years of a civil engineering program, and with the content covering a wide range of rather independent topics, it is necessary to provide a broad-brush treatment without relying on too many prerequisites. The students subsequently take more detailed courses in soils, rocks, concrete, steel, etc. that offer higher-level coverage.

All four co-authors are passionate about what we do in our respective areas, with excellent track records in teaching and learning. We are also active researchers who are up-to-date with the recent developments. Being young or young at heart, we have a good blend of experience; the young ones are eager to provide good taste and layout that is appealing to the new generation, and the senior ones take charge and contribute through their experiences. Having four co-authors with different backgrounds is one of the strengths here. This has enabled us to develop the chapters with genuine expertise in areas that we have been teaching for years. 